\title{
CABIMENTO DA DENÚNCIA ESPONTÂNEA NO PARCELAMENTO DE DÉBITOS TRIBUTÁRIOS
}

\section{APPROPRIACY OF SPONTANEOUS ACCUSATION IN THE INSTALLMENT OF TAX DEBTS}

\author{
Cristina Zanello"
}

\begin{abstract}
Resumo: A denúncia espontânea assim como o parcelamento de débitos tributários tem uma determinada função no ordenamento jurídico. A busca de seus conceitos e fundamentos é necessária para resolver polêmicas geradas na interpretação das normas que regem os referidos institutos, o que não tem sido observado nas decisões dos tribunais. Criam-se antinomias onde não existem, impedindo que tais institutos venham a cumprir a missão de dar efetividade aos princípios e direitos fundamentais. Vencidos os paradigmas que impedem a interpretação sistemática das regras que informam os referidos institutos, conclui-se que a denúncia espontânea é regra específica que não colide com as regras de parcelamento de débitos tributários, podendo ser aplicada sempre que o sujeito passivo da obrigação tributária tiver a iniciativa de pagar os débitos tributários antes de qualquer procedimento do Fisco, ainda que o pagamento seja em parcelas.
\end{abstract}

Palavras-chave: Parcelamento. Denúncia Espontânea. Interpretação sistemática. Princípio da especialidade.

Abstract: Spontaneous accusation as well as installment of tax debts have a specific function in the legal order. The search for its concepts and foundations is necessary in order to solve controversies generated by the interpretation of the norms that rule such instances, which have not been taken into account by court decisions. Antinomies are created where there is none, preventing such instances from fulfilling the mission of accomplishing fundamental principles and rights. Once the paradigms that prevent the systematic interpretation of the rules that sustain such instances are overcome, it is concluded that the spontaneous accusation is the specific rule that does not collide with the rules of tax debt installment, which can be applied whenever the subject in tax debt has the initiative of paying the debts before any action by the tax authorities, even if the payment is in installments.

Key-words: Installments. Spontaneous Accusation. Systematic Interpretation. Principle of Speciality.

Advogada especialista em direito empresarial, tendo atuado com gerente jurídico de grandes empresas nacionais e multinacionais, mestre em Direito Negocial pela Universidade Estadual de Londrina, membro do Instituto de Direito Tributário de Curitiba, Membro da Comissão de Direito Tributário da OAB/PR, Professora universitária. Endereço eletrônico: czanello@terra.com.br 


\section{INTRODUÇÃO}

Equívocos ocorrem na interpretação das normas jurídicas, quando a análise do texto legal desconsidera os conceitos e os fundamentos dos institutos que envolvem uma suposta antinomia. É o que tem ocorrido com a aplicação da denúncia espontânea nas hipóteses de parcelamento de débitos tributários. A interpretação está arraigada aos parâmetros positivistas influenciados por modelos de Estado ultrapassados, em que se percebe o equívoco em elevar a arrecadação do Estado ao patamar de interesse público primário quando na verdade trata-se de interesse público secundário, ou seja, apenas um instrumento para alcançar o interesse público primário como, por exemplo, a construção de obras públicas, educação, saúde etc.

A esse passo, vale lembrar as palavras o insigne jurista português, Vitor Faveiro, que em sua obra "Estatuto do Contribuinte" afirma que o volume da arrecadação não está atrelada ao volume das despesas públicas nos seguintes termos: "O direito tributário, apesar de ser ramo do direito financeiro não atribui à receita tributária como mera dependência da despesa pública" (FAVEIRO, 2002, p. 99). Segundo o autor A pessoalidade do sistema tributário retira da receita tributária a dependência da despesa pública, ou seja, o objeto e o volume das despesas financeiras orçadas não legitimam a exigência e nem determinam o volume das receitas tributárias impostas pelo legislador e cobradas dos indivíduos pela autoridade fiscal.

A inversão da interpretação evidenciando o valor da arrecadação em detrimento da pessoalidade do sujeito passivo da obrigação tributária que, aliás, é exigência constitucional expressa no $\S 1^{\circ}$, do art. 145 da Constituição Federal, reflete-se na interpretação de todos os institutos do direito tributário traduzindo-se em injustiça fiscal.

O Fisco e o Poder Judiciário possuem entendimento assente quanto à não aplicação da denúncia espontânea no parcelamento de débitos tributários sob os seguintes argumentos:

a) que o parcelamento não consiste em pagamento de tributos, sendo uma espécie de moratória;

b) que o Código Tributário Nacional estaria estabelecendo que a denúncia espontânea, que compreende a exclusão da multa, só ocorreria com o pagamento integral do tributo devido; e

c) que o $\S 1^{\circ}$, do Art. 155-A do CTN não estaria admitindo a exclusão de multa e juros no parcelamento de débitos tributários sendo, portanto, vedada a denúncia espontânea neste caso. 
No entanto, falta consistência jurídica aos argumentos acima expostos pelos seguintes motivos:

\section{O PARCELAMENTO E A MORATÓRIA}

O primeiro equívoco com relação ao conceito de parcelamento de débitos tributários ocorre por boa parte da doutrina que diz ser este instituto, uma espécie de moratória parcelada.

Analisando-se a legislação tributária, observa-se que em 1975 o legislador já atribuía, expressamente, autonomia ao parcelamento de débitos tributários. No Art. 10 da Lei Complementar no 24/1975, nota-se o tratamento distinto entre o parcelamento e a moratória ao estabelecer que as condições gerais definidas nos convênios "poderão conceder unilateralmente anistia, remissão, transação, moratória, parcelamento de débitos fiscais, [...]”.

O Art. 154 e parágrafo único e o Art. 155 do CTN demonstram que os encargos, como juros e multa apenas são exigidos em casos de dolo e simulação, casos que descaracterizam a moratória.

Art. 154. Salvo disposição de lei em contrário, a moratória somente abrange os créditos definitivamente constituídos à data da lei ou do despacho que a conceder, ou cujo lançamento já tenha sido iniciado àquela data por ato regularmente notificado ao sujeito passivo.

Parágrafo único. A moratória não aproveita aos casos de dolo, fraude ou simulação do sujeito passivo ou do terceiro em benefício daquele.

No caput do Art. 154 fica evidenciado que a moratória é concedida antes da data do vencimento do tributo porque abrange débito constituído e exigível através do lançamento. Não há menção ao não cumprimento ou à data do vencimento do tributo. No parágrafo único, a moratória não é concedida em caso de ato ilícito culpável do devedor. Já entre as regras do parcelamento de débitos tributários não há esta previsão, sendo concedido inclusive para devedores que cometem atos ilícitos. Na verdade esta regra da moratória deveria ser aplicada subsidiariamente à legislação do parcelamento de débitos tributários para a sua concessão.

Art. 155. A concessão da moratória em caráter individual não gera direito adquirido e será revogado de ofício, sempre que se apure que o beneficiado não satisfazia ou deixou de satisfazer as condições ou não cumprira ou deixou de cumprir os requisitos para a concessão do favor, cobrando-se o crédito acrescido de juros de mora:

I - com imposição da penalidade cabível, nos casos de dolo ou simulação do beneficiado, ou de terceiro em benefício daquele; [...].

De acordo com o dispositivo supratranscrito, a moratória é um favor pelo qual, o Estado concede o diferimento do prazo de pagamento antes da data do 
vencimento, excluídos os encargos. Os juros de mora acrescidos de penalidade, apenas serão exigidos em caso de não cumprimento, por parte do contribuinte, dos requisitos ou condições exigidos na concessão da moratória. Vale dizer, os encargos só serão exigidos em caso de revogação da moratória conforme expresso no caput do Art. 155 do CTN.

Portanto, se houver inadimplemento na moratória parcelada haverá incidência de juros e multa, o que configura a revogação da moratória. Então, o valor do crédito do Estado será composto do valor principal do tributo devido, acrescido dos encargos em razão da mora e caso seja pago em parcelas constituirá o parcelamento de débitos tributários. Neste sentido Bernardo Ribeiro de Moraes (1997, v. 2, p. 412) afirma que "a moratória não se confunde com a concessão do parcelamento, pois a moratória não comporta encargos e o débito fiscal, no caso, ainda não se acha vencido".

Acertadamente, Bernardo Ribeiro de Moraes (1997, v. 2, p. 410-412) afirma: "Ao conceder moratória, o credor adia a cobrança da dívida, renovando o prazo para o seu adimplemento antes de o devedor incidir em mora”. E acrescenta:

Num certo sentido, podemos dizer que a moratória é o oposto da "mora". A pessoa que deixa esgotar o prazo de adimplemento da obrigação, incorre em mora. A moratória implica justamente em contrário, na dilação do referido prazo, na morte da mora, não admite que o devedor incorra em mora. (MORAES, 1997, v. 2, p. 410).

O crédito tributário objeto de parcelamento, não basta apenas estar constituído no forma do Art. 154 do CTN (moratória); deve estar atrasado, pois sujeita-se à atualização monetária, à multa e aos juros legais, até a data do efetivo recolhimento de cada parcela porque é aplicada aos casos de débitos constituídos e vencidos.

Sendo a moratória, ainda que concedida na forma parcelada, o oposto da mora, não há como confundi-la com o parcelamento de débitos tributários. A moratória parcelada aplica-se aos créditos tributários constituídos, exigíveis e não vencidos. Já o parcelamento de débitos tributários aplica-se aos créditos constituídos, exigíveis e vencidos, passando o sujeito passivo a ser qualificado como devedor.

Segundo os Arts. 152 e 153 do CTN, a moratória pode ser concedida em caráter geral ou individual.

A concessão da moratória em caráter geral decorre normalmente de uma causa de ordem estrutural que é fator suficiente para impedir o cumprimento das obrigações como, por exemplo, as enchentes, a seca, situações de calamidade pública etc., pois segundo o parágrafo único do Art. 152 do CTN, a moratória 
pode limitar-se à determinada região ou classe de sujeitos passivos. Isto não ocorre com o parcelamento de débitos tributários, porque o destinatário é sempre o sujeito passivo devedor.

A principal característica da moratória é a dilação de prazo para o pagamento dos débitos tributários, concedida antes da data do vencimento para o pagamento do tributo, que pode ser realizado em parcelas. Como não há mora, não há cobrança de encargos. É neste ponto que se torna indubitável a diferença entre a moratória e o parcelamento de débitos tributários como se vê claramente no Art. 155 e no Art. 155-A e seu $\S 1^{\circ}$ do CTN, antes transcrito.

Por sua vez, o parcelamento de débitos tributários é concedido para que o contribuinte salde sua dívida, a qual é constituída pelo valor do tributo acrescido de juros de mora, correção monetária, quando for o caso, e multa. Estes encargos podem ser reduzidos a critério do poder tributante.

É necessário salientar que o parcelamento do crédito do Estado, apurado e não vencido, é moratória. É o que ocorre, por exemplo, no momento da apuração do Imposto sobre a Propriedade de Veículos Automotores - IPVA (Decreto 12.658/2008 do Estado do Paraná, Art. 2oㅡㄹ II e $\left.\S 3^{3}\right)^{1}$. O poder tributante concede ao contribuinte a opção de pagar este imposto à vista com um desconto ou em parcelas, sem quaisquer encargos adicionais. Esta opção caracteriza a moratória por se realizar antes da data do vencimento para o pagamento do tributo. Desse modo, na moratória, o contribuinte não está em mora.

Essa distinção é relevante porque afeta os próprios fundamentos do parcelamento de débitos tributários que por não ser um favor fiscal, não ofende o princípio da isonomia com relação aos que pagam os tributos pontualmente.

Logo, o parcelamento de débitos tributários não se confunde com a moratória. Ao contrário da moratória, o parcelamento não é um favor fiscal, pois implica no pagamento de encargos em razão da mora. Ademais, terá maior capacidade de competição no mercado aquele que paga pontualmente os

${ }^{1}$ Decreto n. 12.659/2008 do Estado do Paraná

Art. $2^{\circ}$ O IPVA relativo ao exercício de 2009 , correspondente a veículos usados, pode ser pago mediante uma das seguintes formas:

I - pagamento em parcela única, com desconto de dez por cento;

II - pagamento em até três parcelas mensais e iguais.

$[\ldots]$

O inciso II refere-se à moratória parcelada porque não já incidência de juros e multa. $\S 3^{\circ} \mathrm{O}$ atraso no pagamento de qualquer parcela implica a atualização do débito e o acréscimo de juros de mora e multa, na forma da lei. (Este parágrafo reza sobre o parcelamento de débitos tributários). 
tributos por apresentar melhores condições financeiras para investir no setor produtivo.

\section{DEFINIÇÃO DOS INSTITUTOS DE DIREITO PRIVADO}

O parcelamento é um instituto de direito privado definido nos Arts. 314 e 319 do Código Civil, como forma de pagamento, conforme se depreende dos seus termos:

Art. 314. Ainda que a obrigação tenha por objeto prestação divisível, não pode o credor ser obrigado a receber, nem o devedor a pagar, por partes, se assim não se ajustou.

Esse dispositivo estabelece que o pagamento parcelado é liberalidade do credor e não um direito do devedor.

Art. 319. O devedor que paga tem direito a quitação regular, e pode reter o pagamento, enquanto não lhe seja dada.

Então, o devedor que realiza o pagamento em parcelas tem o direito de reter o pagamento enquanto o credor não lhe der a quitação da parcela antecedente.

De conseguinte, conclui-se que o pagamento pode ser parcelado, se assim for ajustado com o credor; neste caso, o efeito de extinção da obrigação só ocorrerá com o pagamento da última parcela, constituindo assim o pagamento total do débito.

Nessa linha, Silvio de Salvo Venosa (2005, v. 2, p. 205) ensina: "Só existirá solução da dívida com a entrega do objeto da prestação. Se a prestação é complexa, constante de vários itens não se cumprirá a obrigação enquanto não atendidos todos.” Desse modo, sendo o cumprimento da obrigação, no pagamento complexo ou diferido, a obrigação apenas se extinguirá com o cumprimento de todos os itens ou de todas as parcelas.

Logo, não há fundamento na confusão entre quitação da obrigação com o pagamento do débito. Pagamento é o ato de cumprimento da obrigação que pode ser integral à vista ou diferida, em parcelas.

Ademais, o parcelamento como regime de pagamento conforme estabelece o Código Civil, é conceito que deve ser respeitado pelo direito tributário por força do Art. 110 do Código Tributário Nacional:

Art. 110. A lei tributária não pode alterar a definição, o conteúdo e o alcance de institutos, conceitos e formas de direito privado, utilizados, expressa ou implicitamente, pela Constituição Federal, pelas Constituições dos Estados, ou pelas Leis Orgânicas do Distrito Federal ou dos Municípios, para definir ou limitar competências tributárias. 
Neste contexto, traz-se à colação os argumentos de Aurora Tomazini de Carvalho (2005, p. 29) quanto ao conceito de parcelamento de débitos tributários:

[...] parcelamento é uma forma para se efetuar o pagamento de um tributo, é um procedimento para a realização do pagamento. Em algumas oportunidades o Estado cria leis, dando oportunidade aos contribuintes, que se subsumirem a determinadas condições, de efetuar o pagamento de seus créditos de forma parcelada. Nestes casos o parcelamento é visto como uma norma geral e abstrata que prescreve um procedimento para o pagamento do tributo devido (grifado).

Portanto, o parcelamento de débitos tributários é um regime de pagamento sendo possível a admissão da denúncia espontânea porque o Código Tributário Nacional não exige que haja a quitação do débito para a sua concessão.

No Art. 138 do Código Tributário Nacional não está evidenciado que a exclusão da multa ocorre exclusivamente com o pagamento integral do tributo devido, pois exige para a referida exclusão, apenas o pagamento do tributo e não o seu pagamento integral, como se observa nos seus termos abaixo transcritos:

Art. 138. A responsabilidade é excluída pela denúncia espontânea da infração, acompanhada, se for o caso, do pagamento do tributo devido e dos juros de mora, ou do depósito da importância arbitrada pela autoridade administrativa, quando o montante do tributo dependa de apuração.

Parágrafo único. Não se considera espontânea a denúncia apresentada após o início de qualquer procedimento administrativo ou medida de fiscalização, relacionados com a infração.

O dispositivo legal fala do pagamento do tributo devido ou do depósito da importância arbitrada pela autoridade administrativa, o que não evidencia a exigência de pagamento integral, mas se faz necessário que haja iniciativa do devedor para o início do pagamento, ainda que seja parcelado, antes de qualquer procedimento administrativo ou medida de fiscalização.

Esta conclusão se extrai do fato de o Código Tributário Nacional utilizar a expressão pagamento para identificar o ato de entregar, de dar o valor do tributo e por vezes utilizar a expressão pagamento no sentido de quitação, ou seja, pagamento integral.

Quando o sentido é de quitação a expressão pagamento vem acompanhada da palavra integral conforme demonstrado abaixo:

Art. 158. O pagamento de um crédito não importa em presunção de pagamento:

I - quando parcial, das prestações em que se decomponha;

II- quando total, de outros créditos referentes ao mesmo ou a outros tributos. (grifado).

A expressão pagamento total ou integral está sempre ligada à extinção do 
crédito tributário, porque tão-somente o pagamento o sentido de quitação extingue o crédito tributário como confirmado pelo Art. 156, I do CTN.

No caput do Art. 158 a expressão pagamento aparece por duas vezes, sendo que a primeira menção refere-se ao ato de pagar, de entregar ao credor/Fisco e a segunda menção refere-se à quitação.

Nos incisos desse dispositivo está evidenciado que o pagamento pode ser parcelado ou integral.

\section{PRINCÍPIO DA ESPECIALIDADE}

Quanto ao argumento de que o $§ 1^{\circ}$, do Art. 155-A do CTN não admitiria a exclusão de multa e juros nos casos de parcelamento de débitos tributários e, portanto, seria vedada a denúncia espontânea, também não deve prevalecer.

$\mathrm{Na}$ verdade tal interpretação implica, em princípio, na antinomia entre o Art. 138 do Código Tributário Nacional que exclui a responsabilidade do devedor e consequentemente a aplicação da multa nos casos em que este realiza o pagamento do tributo devido, antes de qualquer iniciativa da autoridade fazendária e o Art. 155-A que veda a exclusão de juros e multa, salvo disposição legal em contrário.

Art. 155-A. O parcelamento será concedido na forma e condição estabelecidas em lei específica.

$\S 1$ o Salvo disposição de lei em contrário não exclui juros e multas.

A aparente antinomia que possa haver entre o $\S 1^{\circ}$, do Art. 155-A e o Art. 138 e seu $\S 1^{\circ}$, ambos do CTN é resolvida pela aplicação do princípio da especialidade, segundo Maria Helena Diniz (2003, p. 33) :

[...] O de especialidade (lex specialis derogat legi generali), que visa a consideração da matéria normada, com o recurso aos meios interpretativos. Entre a lex specialis e a lex generalis há um quid specie ou uma gens au speci. Uma norma é especial se possuir em sua definição legal todos os elementos típicos da norma geral e mais alguns de natureza objetiva ou subjetiva, denominados especializantes.

A regra geral é o pagamento em atraso e a cobrança dos encargos punitivos. Assim o parcelamento é forma de pagamento que ocorre quando o devedor está em mora porque sobre o valor do débito incidirão os juros e a multa (encargo punitivo), expressos no Art. 155-A, § 1ํ do CTN. A regra do Art. 138 do CTN, denúncia espontânea é mais específica porque fala da hipótese de exclusão da multa no caso de o devedor procurar o Fisco para cumprir a obrigação tributária, antes dos atos de fiscalização e cobrança pelo Estado. O elemento especializante é o pagamento fora do prazo e a regra geral é a incidência de multa. A regra específica é a hipótese da exclusão da multa. 
Como a regra geral do art. 155-A, $\S 1^{\circ}$, do CTN, surgiu depois da regra específica do Art. 138 e $\S 1^{\circ}$, do CTN, tem sido interpretada como uma antinomia de segundo grau entre o critério cronológicio (norma editada posteriormente) e o critério da especialidade. Ad argumentandum, por este raciocínio o conflito se resolveria com a aplicação do princípio da especialidade que prevalece sobre o critério cronológico, conforme afirma Maria Helena Diniz:

Em caso de antinomia entre o critério de especialidade e o cronológico, valeria o meta critério lex posterior generalis non derogat priori speciali, segundo o qual a regra de especialidade prevaleceria sobre a cronológica.

Para Bobbio, a superioridade da norma especial sobre a geral constitui expressão da exigência de um caminho da justiça, da legalidade à igualdade, por refletir, de modo claro, a passagem da lei geral à exceção como uma passagem da legalidade abstrata à equidade. (DINIZ, 2003, p. 40-1).

No caso de subsistir a interpretação de que estaria ocorrendo um conflito entre as duas regras, a solução também existe pelo argumento do princípio da especialidade, prevalecendo o reconhecimento da denúncia espontânea para os casos de parcelamento de débitos tributários.

\section{O PARCELAMENTO E OS FUNDAMENTOS DA DENÚNCIA ESPONTÂNEA}

Contudo, por outro enfoque, não há qualquer conflito entre as duas regras do CTN em questão, porque o Art. 155-A foi inserida para trazer expressamente a definição do parcelamento de débitos tributários que antes era confundida com uma espécie de moratória, sendo que em seu $\S 1^{\circ}$ estabelece que poderá sim, haver exclusão da multa caso haja disposição legal em contrário, o que admite no caso específico da iniciativa do devedor anterior ao do Fisco a aplicação da denúncia espontânea conforme o Art. 138 e $§ 1^{\circ}$, do CTN.

Finalmente, corrobora com os argumentos acima a observação dos fundamentos da denúncia espontânea e do parcelamento de débitos tributários. A denúncia espontânea tem por fundamento a compensação das despesas que o Estado teria com a cobrança administrativa e judicial do débito tributário, excluindo a multa do valor do principal com a iniciativa do devedor em realizar o pagamento anteriormente à atividade do Fisco. Este objetivo pode ser cumprido com o pagamento em uma quota ou em parcelas. Caso o devedor incorra em inadimplência do parcelamento o valor do débito voltará ao estado quo ante, incluindo a multa antes excluída no valor do débito a ser cobrado pela Fazenda.

É necessário lembrar que quando o devedor está em dificuldades financeiras busca o parcelamento de débitos tributários em razão da redução de sua capacidade econômica. Sobre estes efeitos, Betina Grupenmacher e Sandra Barbon Lewis (2000, p. 25) afirmam: 
[...] empresas que nunca deixaram de recolher tributos devidos e que sempre mantiveram perante o fisco uma postura acima de qualquer crítica, chegam à situação de tamanha dificuldade financeira que efetuar o pagamento de tributos, em alguns momentos, torna-se absolutamente inviável.

As autoras ao defenderem a aplicação da denúncia espontânea no parcelamento de débitos tributários, afirmam que as empresas que procuram regularizar sua situação perante o fisco confessando, inclusive, seus débitos fiscais, recebem o mesmo tratamento que aquelas que permanecem na ilegalidade sem a intenção buscar a regularização.

Diante do exposto conclui-se que o parcelamento de débitos tributários é um regime de pagamento que possibilita a arrecadação (ZANELLO, 2008, p. 7893) do Estado em momentos de crise do sujeito passivo, não havendo qualquer contradição com a aplicação da denúncia espontânea com o pagamento da primeira parcela.

\section{REFERÊNCIAS}

CARVALHO, Aurora Tomazini. Crimes contra a ordem tributária: a necessidade de esgotamento da esfera administrativa para a propositura da ação penal; os efeitos do parcelamento do crédito tributário sobre a punibilidade penal. In DI SANTI, Eurico Marcos Diniz de (Coord.). Segurança jurídica na tributação e estado de direito. II Congresso Naciontla de Estudos Tributários. São Paulo: Noeses, 2005.

DINIZ, Maria Helena. Conflito de normas. 5. ed. São Paulo: Saraiva, 2003.

FAVEIRO, Vitor. O Estatuto do Contribuinte: a pessoa do contribuinte no estado social de direto. Coimbra: Coimbra, 2002.

GRUPENMACHER, Betina Treiger; LEWIS, Sandra Barbon. Exclusão da multa em parcelamento de débito fiscal. Revista Dialética de Direito Tributário, São Paulo, n. 56, p. 25-31, maio 2000.

MORAES, Bernardo Ribeiro de. Compêndio de Direito Tributário. 3. ed. Rio de Janeiro: Forense, 1997. v. 2.

VENOSA, Silvio de Salvo. Direito civil: teoria geral das obrigações e teoria geral dos contratos. 5. ed. São Paulo: Atlas, 2005. v. 2.

ZANELLO, Cristina. Normas arrecadadoras tributárias como instrumento de intervenção no domínio econômico. Revista Tributaria e de Finanças Públicas, v. 16, n. 80, p. 78-93, maio/jun. 2008. 